\title{
Possible Mechanism of Spinal T9 Stimulation- Induced Acute Renal Failure: A Virally Mediated Transsynaptic Tracing Study in Transgenic Mouse Model
}

\section{TO THE EDITOR:}

The case report titled "Acute renal failure during a trial of spinal cord stimulation: Theories as to a possible connection" by Larkin et al (1) addressed that spinal T9 stimulation could lead to diminished renal blood flow by the decreased sympathetic input. Renal sympathetic innervation is widely acknowledged to involve the maintenance of fluid homeostasis and modulation of renal hemodynamics. The understanding of spinal cord segments innervating the kidney, and spinal sympathetic innervations and neuronal connections to the kidney is important for studying the possible mechanism of decreased renal sympathetic input during a trial of spinal T9 stimulation. We would like to further complete the discussion of Larkin and colleagues by introducing a virally mediated transsynaptic tracing study in a transgenic mouse model.

The autonomic nervous system plays a prominent role in modulating carbohydrate metabolism (2). The kidneys respond to altered water and sodium availability with a set of homeostatic responses mediated by sympathetic outflow $(3,4)$. The melanocortin-4 receptor (MC4R) is expressed in numerous spinal cord regions, and some findings indicated an important physiologic role for the MC4R in the regulation of renal sympathetic traffic by both leptin and insulin (5). We had characterized projections from the kidney to the spinal cord in adult male MC4R-green fluorescent protein (GFP) transgenic mice by using retrograde tracing techniques of pseudorabies virus (PRV) -614, expressing a novel monomeric red fluorescent protein (mRFP1) under control of the cytomegalovirus immediate early promoter, for direct visualization under a fluorescence microscope (6-10). We found that injections of PRV-614 into the kidney resulted in retrograde infection of neurons in the ipsilateral intermediolateral cell column (IML), the intercalates nucleus (IC), and the central autonomic nucleus (CAN) of the spinal cord, and PRV614-infecting cells were most heavily concentrated in the IML and were distributed sparsely in the IC and CAN of thoracic spinal cord segments T4 to L1, and most PRV-614 labeled cells specifically concentrated in the IML of T9 segment. Otherwise, PRV-614/ MC4R-GFP dual labeled neurons were detected in the IML and IC of the spinal cord (Fig. 1), and most PRV-614/MC4R-GFP labeled cells were found in the T9 segment (Fig. 2).
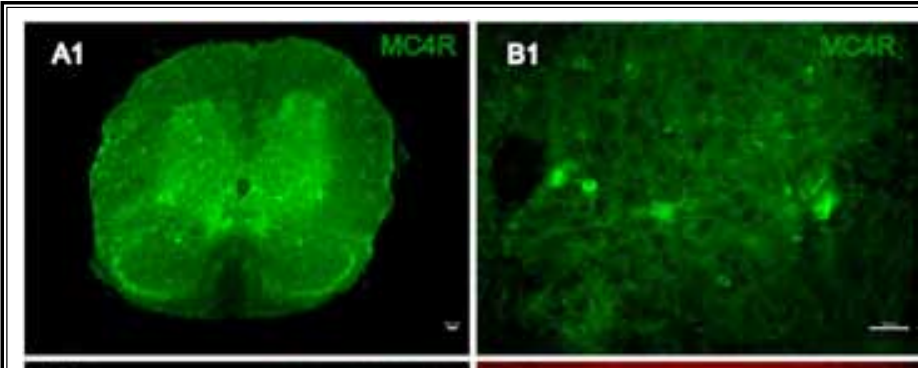

A2
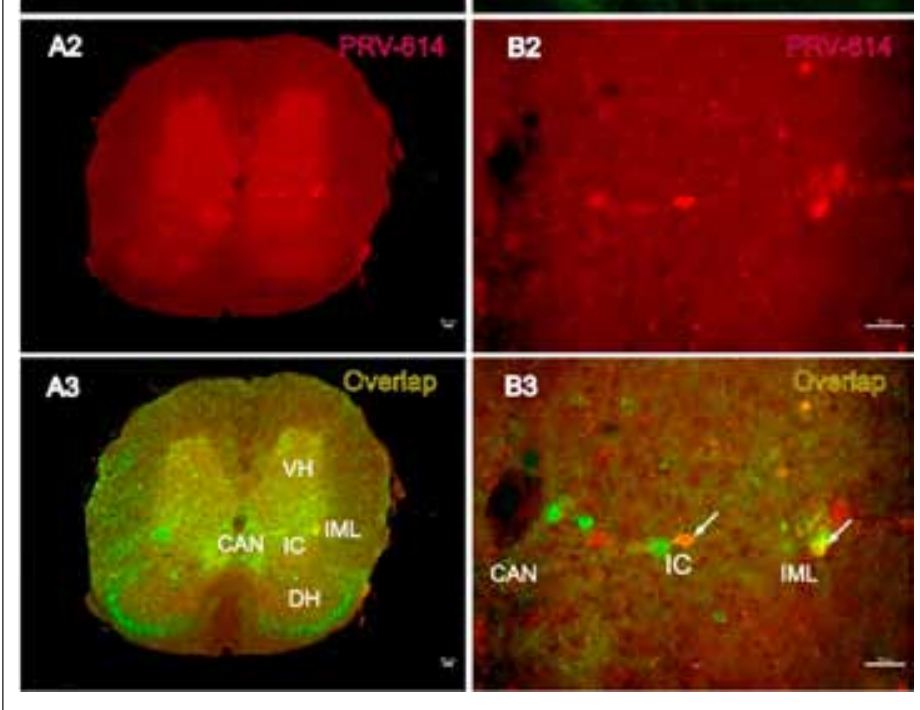

Fig. 1. Transverse section of the spinal cord, 5 days after PRV-614 injection. (A1) MC4R-GFP expressing neurons; (A2) PRV-614 expressing neurons in same section as (A1); (A3) overlap of (A1) and (B1), depicting distribution of MC4R-GFP-IR and PRV-614-bearing neurons. (B1, B2, and B3), amplified views of (A1,A2, and A3), respectively. IML, the intermediolateral cell column; IC intercalates nucleus; CAN, central autonomic nucleus; DH, Dorsal horn; VH, ventral horn. Scale bar: $50 \mu m$. 


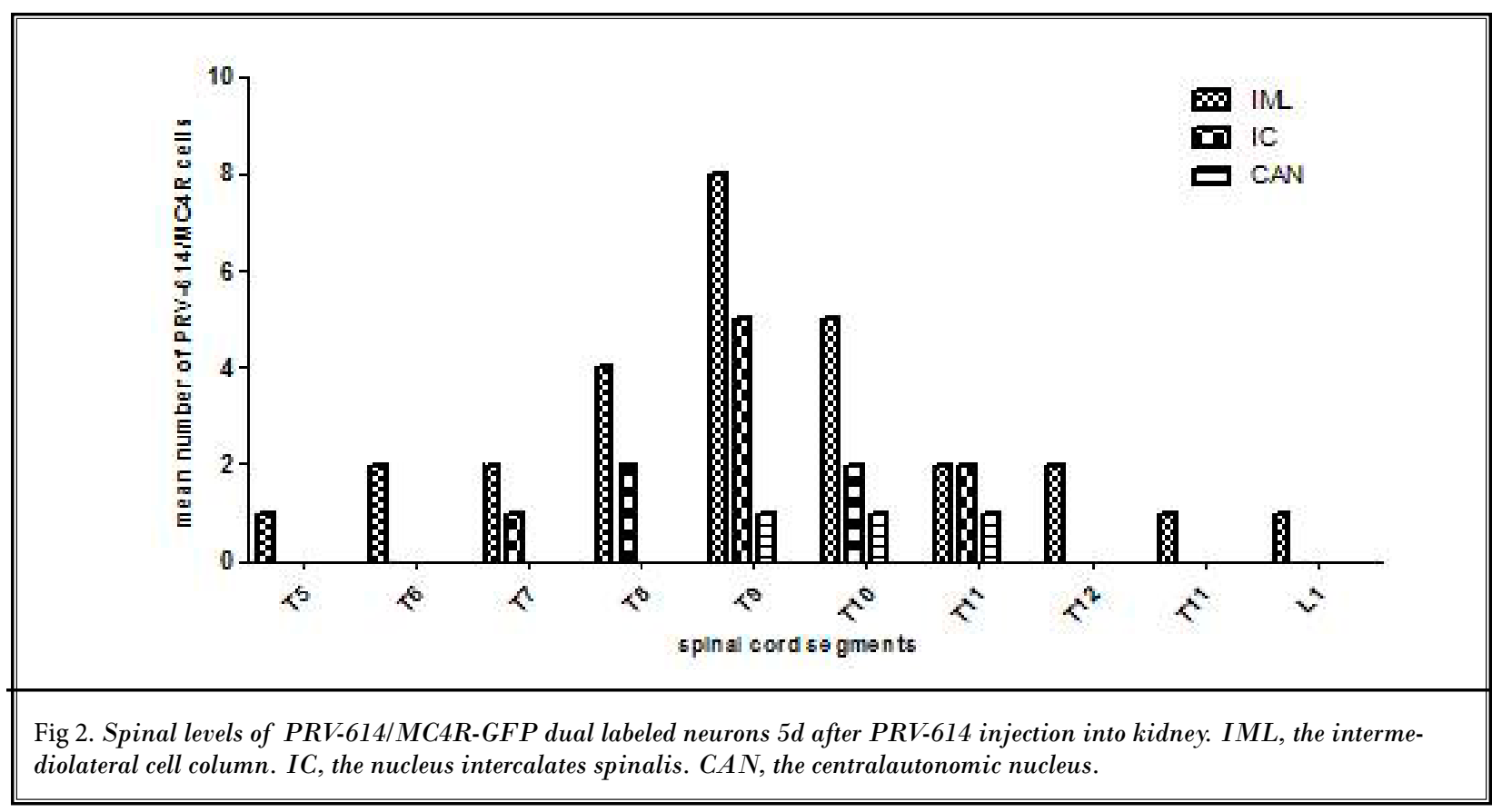

Based on all these findings, we speculate that the T9 spinal cord segment may be primarily involved in sympathetic regulation of renal functions, and spinal T9 stimulation may mainly blockade renal sympathetic innervations, thereby contributing to decreased renal blood flow. Animal studies have shown that the IML of the lower thoracic spinal cord segments (sympathetic kidney innervations T6 to T13) contained sympathetic preganglionic neurons (SPN) (11) and related interneurons, which are involved in processing excitatory and inhibitory influences to the kidney (12). A considerable amount of literature has demonstrated that the IML (13-15) and sympathetic nervous system $(16,17)$ play an important role in the regulation of the kidney. Cano et al (15) demonstrated that the neural control of renal function was exerted by the central nervous system via sympathetic innervations of the kidneys. Otherwise, a growing body of literature supports that sympathetic activity is tightly interconnected via central melanocortinergic pathways involving the MC4R (18-21). These studies indicate that the PRV-614/MC4R-GFP dual labeled neurons of the spinal cord may influence renal function. Our data further suggests that the spinal T9 PRV-614/MC4R-GFP neuronal circuits are involved in the regulation of renal functions.

In summary, the spinal T9 segment is considered a prominent neuronal circuit involved in the regulation of renal functions. Thereby, spinal cord stimulation of T9 may induce diminished renal blood flow (e.g., secondary renal failure) by a reflex mechanism involving the sympathetic chain. Further investigation into the true incidence of secondary renal failure after SCS is warranted.

\section{Acknowledgements}

We gratefully acknowledge Dr. Lynn Enquist for kindly providing us with PRV-614 and Dr. Joel Elmquist (UT Southwestern Medical Center) for providing the MC4R-GFP transgenic mice. This work was supported by grants from National Natural Science Foundation of P.R. China (No. 81071307, 81271766 to H.X), Innovation Project of Huazhong University of Science and Technology (2012TS060 to H.X) and Clinical Key Disciplines Construction Grant from the Ministry of Health of P.R. China.

Hong-Bing Xiang, MD, PhD

Department of Anesthesiology and Pain Medicine, Tongji Hospital

Tongji Medical College

Huazhong University of Science and Technology,

Wuhan, Hubei, 430030

People's Republic of China.

E-mail: xianghongbing@gmail.com 
Cheng Liu, MD

Department of Anesthesiology and Pain Medicine, Tongji Hospital

Huazhong University of Science and Technology,

Wuhan, Hubei, 430030

People's Republic of China.

E-mail: radientg@163.com

Da-Wei Ye, MD, PhD

Cancer Center,

Tongji Hospital, Tongji Medical College,

Huazhong University of Science and Technology,
Wuhan, Hubei, 430030

People's Republic of China

E-mail: dy0711@gmail.com

Wen-zhen Zhu, MD, PhD
Department of Radiology
Tongji Hospital, Tongji Medical College,
Huazhong University of Science and Technology
Wuhan, Hubei, 430030
People's Republic of China.
E-mail: zhuwenzhen@hotmail.com

Wen-zhen Zhu, MD, PhD

Department of Radiology

Huazhong University of Science and Technology

Wuhan, Hubei, 430030

E-mail: zhuwenzhen@hotmail.com

\section{References}

1. Larkin TM, Dragovich A, Cohen SP. Acute renal failure during a trial of spinal cord stimulation: Theories as to a possible connection. Pain physician 2008; 11:681686.

2. Stanley S, Pinto S, Segal J, Perez CA, Viale A, DeFalco J, Cai X, Heisler LK, Friedman JM. Identification of neuronal subpopulations that project from hypothalamus to both liver and adipose tissue polysynaptically. Proc Natl Acad Sci U S A 2010; 107:7024-7029.

3. Huang J, Chowhdury SI, Weiss ML. Distribution of sympathetic preganglionic neurons innervating the kidney in the rat: Prv transneuronal tracing and serial reconstruction. Auton Neurosci 2002; 95:57-70.

4. DiBona GF. Nervous kidney. Interaction between renal sympathetic nerves and the renin-angiotensin system in the control of renal function. Hypertension 2000; 36:1083-1088.

5. Rahmouni K, Haynes WG, Morgan DA, Mark AL. Role of melanocortin-4 receptors in mediating renal sympathoactivation to leptin and insulin. J Neurosci 2003; 23:5998-6004.

6. Glatzer NR, Derbenev AV, Banfield BW, Smith BN. Endomorphin-1 modulates intrinsic inhibition in the dorsal vagal complex. J Neurophysiol 2007; 98:15911599 .

7. Willhite DC, Nguyen KT, Masurkar AV, Greer CA, Shepherd GM, Chen WR. Viral tracing identifies distributed columnar organization in the olfactory bulb. Proc Natl Acad Sci U S A 2006; 103:1259212597.

8. Zhang $Y$, Kerman IA, Laque A, Nguyen $P$, Faouzi M, Louis GW, Jones JC, Rhodes C,
Munzberg $H$. Leptin-receptor-expressing neurons in the dorsomedial hypothalamus and median preoptic area regulate sympathetic brown adipose tissue 16 . circuits. J Neurosci 2011; 31:1873-1884.

9. Xiang HB, Liu C, Guo QQ, Li RC, Ye DW. Deep brain stimulation of the pedunculopontine tegmental nucleus may influence renal function. Med Hypotheses 2011; 77:1135-1138.

10. Ye DW, Li RC, Wu W, Liu C, Ni D, Huang $\mathrm{QB}$, Ma X, Li HZ, Yang H, Xiang HB, Zhang $X$. Role of spinal cord in regulating mouse kidney: A virally mediated trans-synaptic tracing study. Urology 2012; 79:745 e741-744.

11. Badoer E. Role of the hypothalamic pvn in the regulation of renal sympathetic nerve activity and blood flow during hyperthermia and in heart failure. Am J Physiol Renal Physiol 2010; 298:F839-846.

12. Schramm LP, Strack AM, Platt KB, Loewy AD. Peripheral and central pathways regulating the kidney: A study using pseudorabies virus. Brain Res 1993; 616:251262.

13. Card JP, Kobiler O, Ludmir EB, Desai V, Sved AF, Enquist LW. A dual infection pseudorabies virus conditional reporter approach to identify projections to collateralized neurons in complex neural circuits. PLoS One 2011; 6:e21141.

14. Zermann DH, Ishigooka $M$, DoggweilerWiygul R, Schubert J, Schmidt RA. Cen- 21. tral autonomic innervation of the kidney. What can we learn from a transneuronal tracing study in an animal model? The Journal of urology 2005; 173:1033-1038.

15. Cano G, Card JP, Sved AF. Dual viral transneuronal tracing of central auto- nomic circuits involved in the innervation of the two kidneys in rat. J Comp Neurol 2004; 471:462-481.

6. DiBona GF. Neural control of the kidney: Functionally specific renal sympathetic nerve fibers. Am J Physiol Regul Integr Comp Physiol 2000; 279:R1517-1524.

17. Salman IM, Ameer OZ, Sattar MA, Abdullah NA, Yam MF, Abdullah GZ, Abdulkarim MF, Khan MA, Johns EJ. Renal sympathetic nervous system hyperactivity in early streptozotocin- induced diabetic kidney disease. Neurourol Urodyn 2011; 30:438-446.

18. Liu H, Kishi T, Roseberry AG, Cai X, Lee CE, Montez JM, Friedman JM, Elmquist JK. Transgenic mice expressing green fluorescent protein under the control of the melanocortin-4 receptor promoter. J Neurosci 2003; 23:7143-7154.

19. Greenfield JR, Miller JW, Keogh JM, Henning $E$, Satterwhite JH, Cameron GS, Astruc B, Mayer JP, Brage S, See TC Lomas DJ, O'Rahilly S, Farooqi IS. Modulation of blood pressure by central melanocortinergic pathways. $N$ Engl J Med 2009; 360:44-52.

20. Sayk F, Heutling D, Dodt C, Iwen KA, Wellhoner JP, Scherag S, Hinney A, Hebebrand J, Lehnert $H$. Sympathetic function in human carriers of melanocortin-4 receptor gene mutations. J Clin Endocrinol Metab 2010; 95:1998-2002.

Matsumura K, Tsuchihashi T, Abe I, lida M. Central alpha-melanocyte-stimulating hormone acts at melanocortin-4 receptor to activate sympathetic nervous system in conscious rabbits. Brain Res 2002; 948:145-148. 